\title{
Two-photon scanning microscopy of in vivo sensory responses of cortical neurons genetically encoded with a fluorescent voltage sensor in rat
}

\author{
Kurt F. Ahrens ${ }^{1}$, Barbara Heider ${ }^{1 *}$, Hanson Lee ${ }^{2+}$, Ehud Y. Isacoff ${ }^{2}$ and Ralph M. Siegel ${ }^{1 *}$ \\ ' Center for Molecular and Behavioral Neuroscience, Rutgers, The State University of New Jersey, Newark, NJ, USA \\ 2 Department of Molecular and Cell Biology, University of California, Berkeley, CA, USA
}

Edited by:

Edward M. Callaway, California

Institute of Technology, USA

\section{Reviewed by:}

Michael Nitabach, Yale University

School of Medicine, USA

Kenichi Ohki, Kyushu University,

Japan

\section{*Correspondence:}

Barbara Heider, Center for Molecular

and Behavioral Neuroscience, 197

University Avenue, Rutgers

University, Newark, NJ 07102, USA

e-mail: barbara@cortex.rutgers.edu

${ }^{\dagger}$ Present address:

Department of Bioengineering,

University of California, Berkeley,

CA, USA.

${ }^{\ddagger}$ Ralph M. Siegel passed away on

September 2nd 2011.

\begin{abstract}
A fluorescent voltage sensor protein "Flare" was created from a Kv1.4 potassium channel with YFP situated to report voltage-induced conformational changes in vivo. The RNA virus Sindbis introduced Flare into neurons in the binocular region of visual cortex in rat. Injection sites were selected based on intrinsic optical imaging. Expression of Flare occurred in the cell bodies and dendritic processes. Neurons imaged in vivo using two-photon scanning microscopy typically revealed the soma best, discernable against the background labeling of the neuropil. Somatic fluorescence changes were correlated with flashed visual stimuli; however, averaging was essential to observe these changes. This study demonstrates that the genetic modification of single neurons to express a fluorescent voltage sensor can be used to assess neuronal activity in vivo.
\end{abstract}

Keywords: single cell, cortex, two-photon imaging, genetic engineering, vision

\section{INTRODUCTION}

Functional neural circuits have been extensively explored in early sensory areas with a confluence of electrophysiological and neuroanatomical methods. Although electrical recordings in vivo are arguably responsible for the bulk of our understanding of higher cortical areas, combining the morphological, biochemical, and genetic identity of neurons in combination with the multiplicities of function has been challenging. Recent improvements permit neurons to be more selectively labeled and imaged in vivo (Ohki et al., 2005; Ch'ng and Reid, 2011) by the extracellular application of a membrane-permeant calcium dye Oregon Green BAPTA-1 (OGB) in mouse sensory cortex (Stosiek et al., 2003; Mrsic-Flogel et al., 2007). However, this type of calcium labeling has limitations. The dye fades over time and may compromise cell health over repeated applications and thus is not useful in long-term preparations. Furthermore, OGB stains all types of neuron and thus does not allow specific examination of certain neuron types unless it is combined with genetical labeling of specific neuron types (Sohya et al., 2007). On the other hand, calcium dyes like OGB produce a stronger and faster signal compared to various genetically encoded calcium indicators (GECI) (Hendel et al., 2008).

Crick proposed that molecular biology would permit access to particular neuronal types (Crick, 1979). Only more recently has the technology to perform single neuron genetics become available with the advent of retroviruses and other vectors that can control the expression of proteins in vivo (Xiao et al., 1998; Chen et al., 2000; Wickersham et al., 2007). Selection of neurons versus glia, or different types of neuron has become possible either through choice of virus or viral serotype that are selectively neurotropic (Nathanson et al., 2009a,b; Marshel et al., 2010). As well, the control of the expression of reporter genes has matured through development of novel promoters (Reiff et al., 2005).

Genetically encoded fluorescent sensors can be designed to detect various changes related to neural activity: reporters of intracellular $\mathrm{Ca}^{2+}$, for example, Cameleon (Reiff et al., 2005; Liu et al., 2008), or sensors reporting changes in membrane voltage (Baker et al., 2008; Perron et al., 2009b; Lundby et al., 2010). One of the first generation voltage sensors was Fluorescent Shaker (FlaSh), which is a fusion of a voltage-gated Shaker $\mathrm{K}^{+}$channel and a green fluorescent protein (GFP). The dynamics of FlaSh should allow detection of single electrical events. However, in vivo such temporal precision is not possible due to presence of background noise (Siegel and Isacoff, 1997; Guerrero et al., 2002). Another second-generation sensor SPARC (sodium channel protein-based activity reporting construct) was also reported to show fast kinetics and reliably report short depolarizing pulses as short as $2 \mathrm{~ms}$ (Ataka and Pieribone, 2002).

These sensors have been tested extensively in vitro and in cultured neurons but not in vivo under sensory stimulation (Baker et al., 2007). For the current study, neurons in rat visual cortex were transfected to express Flare and imaged in vivo. The study by Baker et al. (2007) reported no functional signals in dissociated hippocampal neurons or HEK 293 cells expressing Flare, whereas the current study showed significant responses in a relatively small percentage of neurons. Differences in expression 
between species (e.g., rats vs. mice) might be responsible for such discrepancy (Xu et al., 2006; Xu and Callaway, 2009). As a first step toward neural circuit analysis in larger animals such as nonhuman primates (Heider et al., 2010), the voltage sensor called Flare, was assessed in a rodent model using two-photon scanning microscopy (TPSM) as described previously (Denk et al., 1994; Jung et al., 2004; Levene et al., 2004). These results demonstrate the feasibility of the sensor and method and thus open the possibility to use similar sensors in other species. This work has been presented in abstract form (Siegel et al., 2007).

\section{MATERIALS AND METHODS}

All experiments were carried out according to NIH Guidelines for Animal Research and approved by Rutgers University Animal Care and Facilities Committee. All procedures followed the guidelines for rodent survival and non-survival surgery.

\section{SENSOR}

The Flare fluorescent voltage sensor is a Kv1.4 variant of FlaSh (Siegel and Isacoff, 1997; Guerrero et al., 2002). By design, Flare is sensitive to supra-threshold events. Flare was created starting with a Kv1.4 potassium channel. The Flare channel was further modified to not pass current by altering amino acid W517F. The linear range for $\mathrm{dF} /$ voltage of Flare was -50 to $-10 \mathrm{mV}$ based on the rational design virus. The distribution of the Flare protein may be similar to the native Kv1.4, which is concentrated with PSD-95 (Walikonis et al., 2000). There is some differential distribution of the related Kv1.2 in dendrites of pyramidal cells (Sheng et al., 1994), but this distribution varied with cell type throughout the central nervous system with some cells showing expression in axonal terminals and the soma. Enhanced yellow fluorescent protein (EYFP) was inserted between V584A and S585S in Kv1.4. The sequence for Flare was inserted into Sindbis plasmids and virus generated in order to transfect neurons in rat cortex.

\section{ANIMAL SURGERY AND VIRUS INJECTION}

In a first recovery surgery, Sprague-Dawley rats (200-800 g) were anesthetized using ketamine $(50 \mathrm{mg} / \mathrm{kg})$, acepromazine $(0.5 \mathrm{mg} / \mathrm{kg})$, xylazine $(5 \mathrm{mg} / \mathrm{kg})$ IP. Atropine $(0.05 \mathrm{mg} / \mathrm{kg}, \mathrm{SC})$ and bupivacaine $(0.2 \mathrm{ml}, \mathrm{SC})$ were administered. A thin layer of ophthalmic ointment was applied on the eyes to avoid dehydration. Anesthesia was maintained by injections of the ketamine mixture every $30 \mathrm{~min}$. The skull was thinned bilaterally exposing the cortex from $4 \mathrm{~mm}$ to $8 \mathrm{~mm}$ posterior of Bregma, and $2 \mathrm{~mm}$ to $6 \mathrm{~mm}$ lateral. A drop of sterile saline was placed on the skull to reduce light scattering, clearly revealing cortical blood vessels. An imaging chamber was constructed using a $3 \times 5 \mathrm{~mm}$ cover slip and orthopedic cement (Smith and Nephews, Richards, Memphis, $\mathrm{TN})$. The chamber was filled with sterile $1 \%$ agar in $0.9 \%$ saline and sealed with cement and bone wax.

After conclusion of the intrinsic imaging experiment, the remaining thinned skull was opened completely. The dura was nicked at the injection locations to allow the glass pipette $(10 \mu \mathrm{m}$ tip diameter) to be lowered into the cortex. A total amount of 1-2 $\mu l$ Sindbis Flare was injected using a Picospritzer pressure system. One to five injections were made into the cortex at depths ranging from $1000 \mu \mathrm{m}$ to the surface. Locations were selected based upon the cortical activation maps and scarcity of blood vessels. Bilateral injections were made in most cases. The muscle and skin tissue was pulled over the craniotomy and the skin stapled. Antibiotic ointment and a local anesthetic were applied on the skin margin, and the animal allowed recovering in its home cage.

Eighteen to Thirty-six hours after the injection procedure, the animal was anesthetized again for a non-survival surgery, and placed in a modified stereotaxic device for two-photon imaging. The same anesthesia drugs were used as for the survival surgery, as described previously. The incision was reopened and the dura completely resected to expose the cortex. Grounding and reference screws were attached to the skull, and a monopolar electrode placed onto the cortical surface within $1 \mathrm{~mm}$ of the recording site. This allowed simultaneous recordings of visually evoked potential during the scanning. An imaging chamber was constructed again with agar, a glass cover, orthopedic cement and bone wax, as described above. The stereotaxic device with the rat was placed under the two-photon scanning microscope. At the end of the experiment (3-5 h), an overdose of sodium pentobarbital $(125 \mathrm{mg} / \mathrm{kg} \mathrm{IP})$ was administered and standard transcardial perfusion with $4 \%$ formalin in saline was performed.

Confocal images of fixed sections were obtained using a BioRad MRC-1024 laser-scanning microscope. Intensity profiles of confocal images were calculated using the "plot profile" procedure (line selections) of ImageJ Software (version 1.38; http://rsb.info.nih.gov/ij/).

\section{INTRINSIC IMAGING AND TWO-PHOTON SCANNING}

Intrinsic optical imaging was performed according to previously published principles for non-human primates (Siegel et al., 2003; Heider et al., 2005) with slight modifications for rodents. A custom built macroscope was utilized with an Optical Imaging 2001 system (Optical Imaging Co., Rehovot, Israel). The vasculature was visualized using $540 \mathrm{~nm}$ green light to determine the depth of the cortical surface. Illumination for intrinsic signal imaging was at $605 \mathrm{~nm}$ after focusing down $300 \mu \mathrm{m}$ from the surface. Rats were fitted with goggles made from adjustable material to eliminate light leakage from the visual stimulus. Visual stimulation was provided via a combination of four miniature LEDs (E100; Gilway, Woburn, MA): red (625 nm), blue (465 nm), violet $(420 \mathrm{~nm})$, and ultraviolet $(375 \mathrm{~nm})$. These wavelengths were chosen to cover the entire range to which rat photoreceptors are selective (Jacobs et al., 2001). The light was passed through a fiber optic that was directly apposed to the cornea providing full field illumination in one eye. After a baseline period of $1000 \mathrm{~ms}$, the stimulus was switched on for $500 \mathrm{~ms}$ and then turned off. Images were collected at $7 \mathrm{~Hz}$ for a total duration of $5200 \mathrm{~ms}$. The data were converted into the Khoros (Khoral Inc., Albuquerque, NM) format and regions of interest (ROI) were analyzed. Signals were expressed as percentage changes from baseline, which consisted of the $500 \mathrm{~ms}$ before stimulus onset.

The two-photon scanning microscope was custom-built according to published design (Tsai et al., 2002). A Mai Tai Ti:sapphire Laser (Spectra-Physics, Mountain View, CA) tunable from 700 to $1020 \mathrm{~nm}$ projected a beam into a double telescope to reshape it, a half-wave plate and polarizing beam splitter to alter the power of the beam, galvanometer scanning mirrors 
and drivers (Cambridge Technology, Cambridge, MA), scanning and tube lenses, and dichroic mirrors (720DCXXR dichroic, HQ535/40-2P emission; Chroma Technology, Rockingham, VT). The laser was blocked between trials using a mechanical Uniblitz shutter. The two-photon microscope was fitted with either a $60 \times$ LUM Plan 0.9 NA (Olympus, Center Valley, PA) or a $40 \times$ PlanNeofluar 0.8 NA (Zeiss, Oberkochen, Germany) water immersion objective. For excitation of the EYFP an emission wavelength of $920 \mathrm{~nm}$ was used. Photons emitted by fluorescent sensor were measured with a photomultiplier tube (PMT) modules (H7710 13; Hamamatsu, Bridgewater, NJ). Current was converted to voltage using a low-noise current preamplifier (model SR570, Stanford Research Systems, Sunnyvale, CA) and digitized with a National Instruments A-D converter. The scanning signals and the A-D converter were controlled and synchronized using Labview-based software (Nguyen et al., 2006). The stored binary image files were analyzed offline using Khoros Package (AccuSoft Corporation, Northborough, MA) in conjunction with custom Unix shell software. ROIs were selected and averages of the pixels within the ROIs were calculated.

Once a field of neurons was located, a high-resolution structural image was acquired $(512 \times 512$ pixels $)$. For functional imaging, scanning was performed at higher frequency and lower spatial resolution. To analyze the evoked responses, the stimulus was presented at variable ON-OFF periods (20-20, 10-30, 30-10; in frames). Evoked responses were defined as percentage change between $\mathrm{ON}$ and $\mathrm{OFF}$ responses.

ROIs were selected using an automated analysis of labeled regions. The average was computed for a single trial. The mean and standard deviation of the fluorescence signal was computed on a pixel-by-pixel basis for each experimental scan $(\sim 100$ trials). The image was then subjected to a threshold so that all pixels greater than one standard deviation above the mean were indicated. The resulting image was then passed through procedures "vlabel" and "vshape" of the Khoros package to select and reduce the number of regions. Subsequently, the same baseline normalization and statistical analyses were performed. In a few experiments, a manual approach was applied as well to compare and verify the automatic region selection. Rectangular regions containing either neurons or neuropil were delimited by eye and the averaged changes in fluorescence of each manually determined ROI calculated. To assess the responses of each ROI, the average fluorescence during the OFF phase was compared with the fluorescence during the ON phase using a One-Way ANOVA with the type of phase as a categorical variable.

\section{RESULTS}

The main goal of the present study was to examine the structural appearance and functional properties of the genetically encoded fluorescent voltage sensor Flare. Neurons in rat visual cortex were transfected with Sindbis Flare to assess neural activity to visual stimulation in vivo.

\section{STRUCTURAL IMAGING: EXPRESSION OF SINDBIS FLARE}

The expression of Sindbis Flare was examined first in fixed tissue (Figure 1). Fields of neurons from superficial cortex approximately $10-50 \mu \mathrm{m}$ in diameter were easily identified
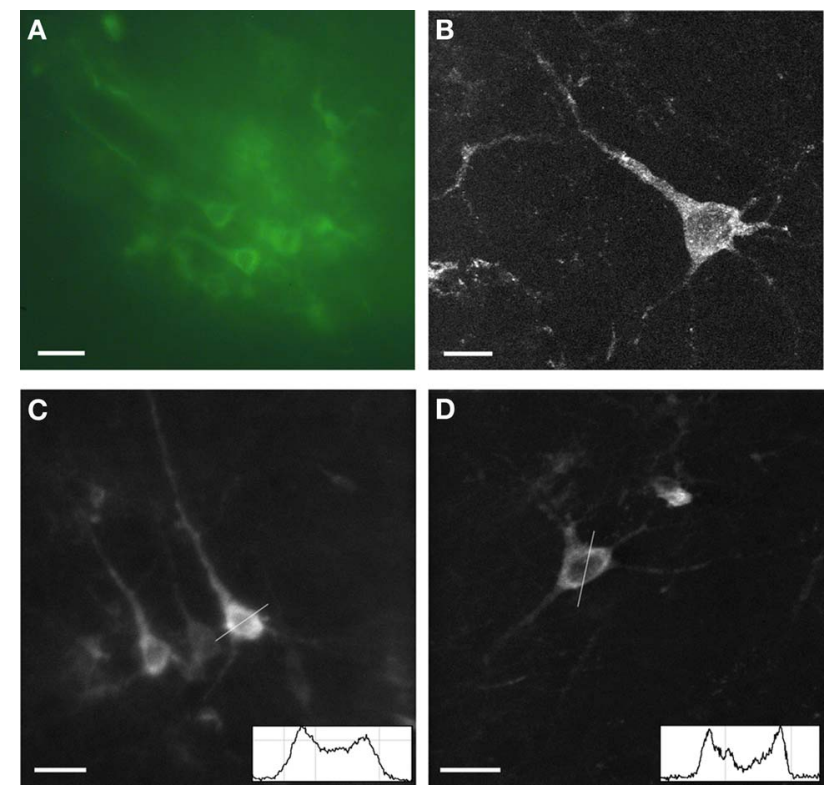

FIGURE 1 | Expression of Sindbis Flare in fixed tissue. (A) Fluorescence microscope image of field of labeled neurons. (B) High power confocal image of a single neuron transfected with Flare (10 $\mu \mathrm{m}$ stack, 0.5 micron sections). (C,D) Confocal images of labeled neurons. No more than third-order dendrites are labeled. Insets show gray scale profiles (membrane brightness relative to cell plasma: 44\%, A; $83 \%$, B; distance; $25 \mu \mathrm{m}$ ) across selected cell bodies. Scale bars, $10 \mu \mathrm{m}$ (A), $5 \mu \mathrm{m}$ (B), $20 \mu \mathrm{m}$ (C,D)

under a conventional fluorescence microscope (Figure 1A). Confocal images of individual neurons confirm that the sensor fluorescence accumulated in the cytosol and in the plasma membrane (Figures 1B-D). Fluorescence intensity profiles (insets in Figures 1C,D) for two selected neurons illustrate that labeling in the plasma membrane was indeed brighter compared to the cytosol, as shown previously (Baker et al., 2007). Fine processes were rarely visible and third order dendrites were never observed. The presence of Flare in the dendrites is as expected given its Kv1.4 origins. The appearance of the labeled neurons suggests that mostly pyramidal neurons were labeled.

Structural images of neurons were obtained with TPSM in vivo in rat cortex $12-36 \mathrm{~h}$ after viral transfection. Low magnification images illustrate the extent of the transformed tissue (Figures 2A,B) and single neurons are visualized at higher magnification (Figures 2C,D). While cell bodies were easily imaged in vivo, cell processes were only rarely observed (Figures $\mathbf{2 A , D}$ ). There were many instances where the background was labeled (Figure 2B), which likely consisted of optically inseparable small processes of the neuropil. The appearance of the sensor with predominant membrane labeling (compare to Figure 1) was rarely seen in vivo (Figure 2C). The Flare signal dropped off rapidly with increasing cortical depth, with signals rarely detectible deeper than $350 \mu \mathrm{m}$. This limitation results from a combination of factors, including available laser power, laser pulse width, efficiency of the detection optics, opacity, and light scattering properties of the tissue. The range of depths for all experiments was between 

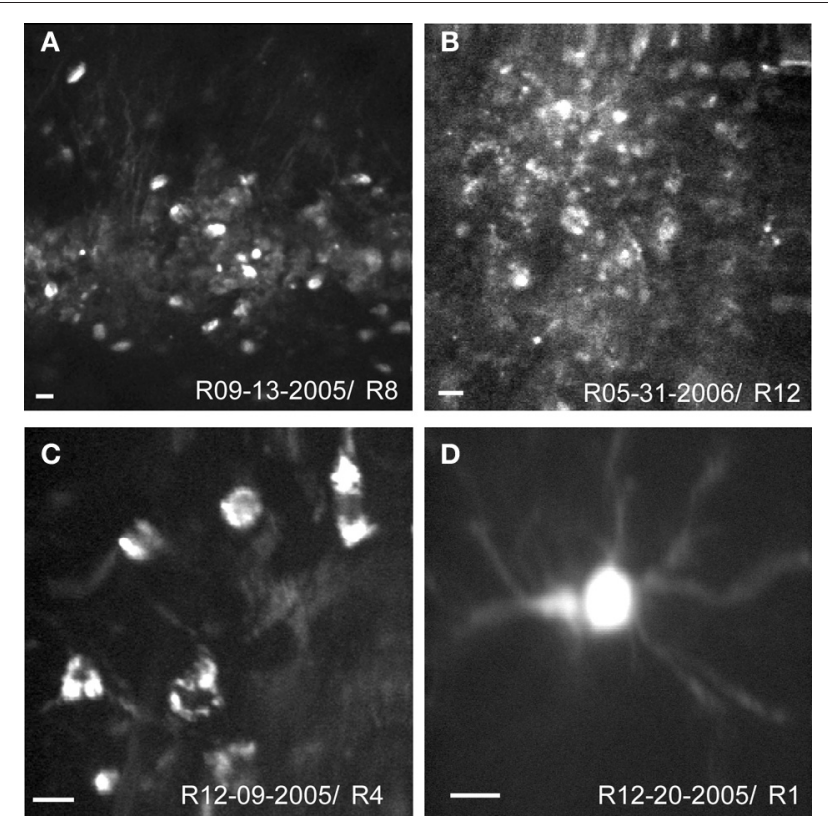

FIGURE 2 | In vivo structural two-photon scanning of Sindbis Flare transfected neurons in rat visual cortex. $(\mathbf{A}, \mathbf{B})$ Labeled cell bodies and neuropil at low magnification. (C,D) High magnification images of soma and dendrites. Scale bars, $10 \mu \mathrm{m}$. Depth of scanning for each example was $90 \mu \mathrm{m}$ (A), $100 \mu \mathrm{m}$ (B), $120 \mu \mathrm{m}$ (C), $340 \mu \mathrm{m}$ (D).

90 and $350 \mu \mathrm{m}$ with the majority of experiments performed at depths between 100 and $200 \mu \mathrm{m}$.

\section{FUNCTIONAL IMAGING: STIMULUS EVOKED SIGNALS}

In 17 of 44 rats, intrinsic imaging was performed prior to the Sindbis Flare injection to optimally target the injection locations in visual cortex (Figure 3A). To measure the intrinsic, hemodynamic signal of the cortex related to a visual stimulus, a short $500 \mathrm{~ms}$ period of monocular, full field ON stimulation was followed by a longer OFF period ( $3700 \mathrm{~ms})$, and the tissue reflectance measured at $605 \mathrm{~nm}$ illumination. In the majority of cases (13/17), the reflectance decreased throughout the measurement period (Figures 3B,C), which manifested as a continuous darkening of the cortex. This is indicative of an overall increase in HbR (deoxyhemoglobin) that can last up to $3000 \mathrm{~ms}$ after stimulus onset (Blood et al., 1995; Martin et al., 2006; Simons et al., 2007; Wang et al., 2011). The locations for the Sindbis Flare injections were based on examination of the intrinsic signal, that is, locations with a strong hemodynamic response and an absence of larger blood vessels were preferred for the subsequent Sindbis Flare injections.

To establish the functionality of the voltage sensor, Flare expressing neurons in rat visual cortex were stimulated with periodic full field visual stimulation. Two examples were chosen to illustrate the typical response of labeled neurons. A high spatial resolution TPSM image of labeled neurons over an $80 \times 80 \mu \mathrm{m}$ region of cortex shows a small cluster of cells (Figure 4A). The time course of fluorescence over brightly labeled ROI were computed by averaging 100 stimulus repetitions. Baseline normalized
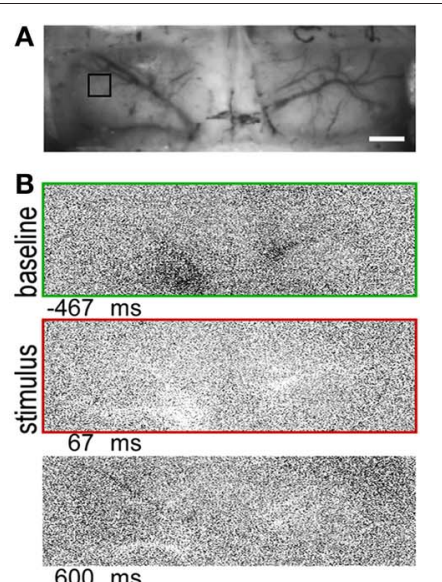

$600 \mathrm{~ms}$

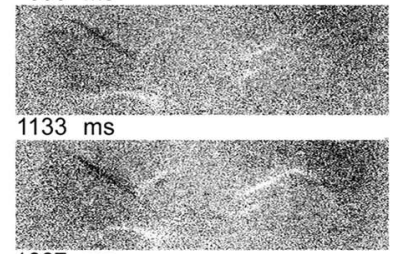

$1667 \mathrm{~ms}$

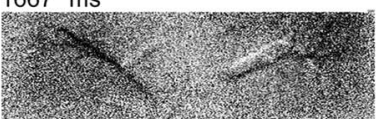

$2200 \mathrm{~ms}$
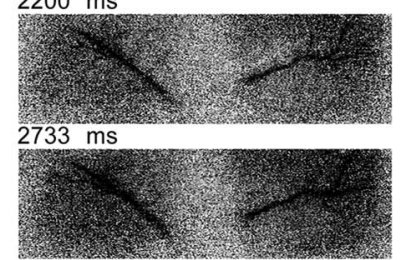

$3267 \mathrm{~ms}$

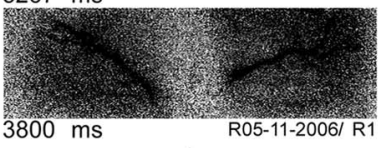

$3800 \mathrm{~ms}$

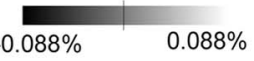

C 0.05

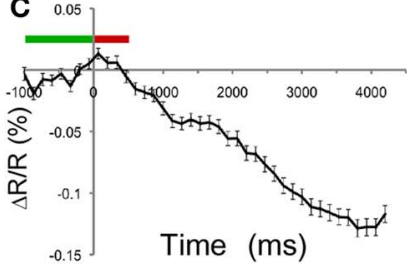

FIGURE 3 | Intrinsic optical imaging of rat visual cortex. (A) Image taken under green $(540 \mathrm{~nm})$ light to visualize vasculature over visual cortex through thinned skull. Scale bar, $1 \mathrm{~mm}$. (B) Time series of intrinsic images taken at $7 \mathrm{~Hz}$ under orange $(605 \mathrm{~nm})$ light. First image, baseline period (green); second image, visual stimulation period (red) (C) Time course (mean \pm standard error) of intrinsic signal in region of interest indicated in (A, black square). Green bar, baseline period; red bar, stimulation period (stimulus onset at time 0).

fluorescence responses for two neighboring neurons are shown. One neuron had a significant $\mathrm{ON}$ response at stimulus onset (Figure 4B, $p<0.01$ ), while another cell approximately $10 \mu \mathrm{m}$ away did not respond (Figure 4C). Simultaneous visually evoked 


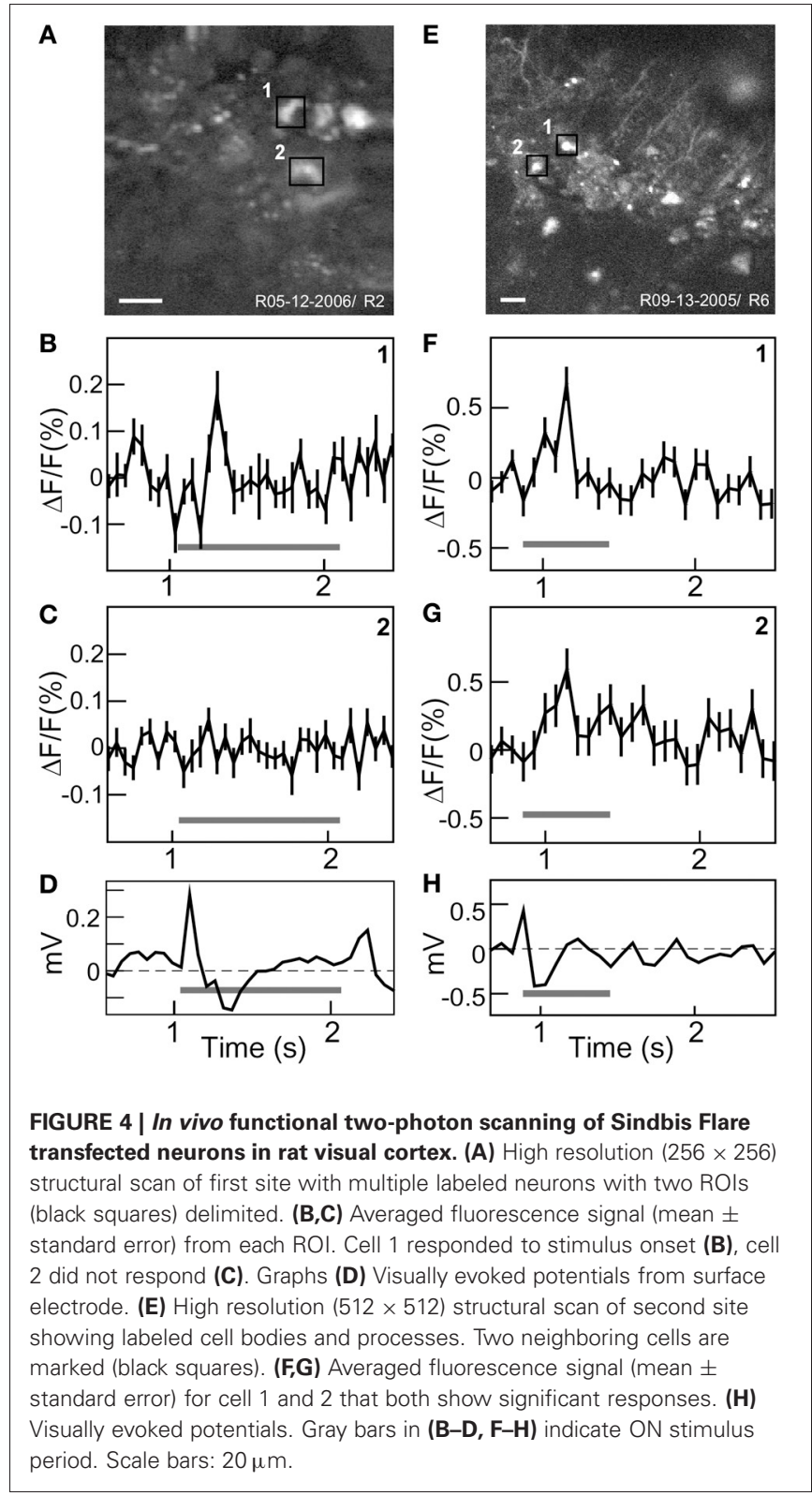

potentials were observed consistently (Figure 4D). The second example shows a $120 \times 120 \mu \mathrm{m}$ field of labeled neurons including labeled processes (Figure 4E). Two selected neighboring neurons showed very similar significant ON responses (Figures 4 F,G; $p<$ 0.01 ). Visually evoked potentials were also recorded (Figure $4 \mathbf{H}$ ). The Flare signal did not bleach over the $220 \mathrm{~s}$ of measurement period, even though the beam was continually scanning.

A total of 44 Sindbis Flare in vivo TPSM experiments were performed of which 12 were discarded for various reasons (e.g., bleeding into imaging field, light leakage from stimulus display). Per experiment 2-3 sites were scanned. Each site always contained several identifiable labeled regions or neurons $($ mean $=10 \pm 5$ ) resulting in a total of 2656 ROIs, which were analyzed quantitatively. To obtain visually evoked responses, substantial averaging was needed ( $\sim 100$ trials per run). Significant ON responses were found in $14.5 \%$ of all ROIs, whereas $6.8 \%$ had significant OFF responses to the full field visual stimulus.

\section{DISCUSSION}

The fluorescent voltage sensor Sindbis Flare was introduced via viral transfection into rat visual cortex to allow in vivo TPSM of individual, labeled neurons. Despite the fact that a previous study reported no functional optical signal using Flare in dissociated hippocampal neurons under patch clamp electrical stimulation (Baker et al., 2007), the current results demonstrate that a substantial proportion of Flare expressing neurons indeed showed significant changes in fluorescence to sensory stimulation. Differences in preparation, species, and imaging technique could well account for these differences.

\section{RATIONAL DESIGN OF SENSOR}

The original design of Flare was based on the current understanding of the properties of Kv1.4 channel, and was engineered to be linear for the voltage range of -50 to $-10 \mathrm{mV}$. During action potentials, the Flare signal is supposed to saturate at its maximum emission. Based on the time course of Flare from in vitro studies and its voltage selectivity (Guerrero et al., 2002), we interpret the Flare signal as an approximation to the mean firing rate. Both increases and decreases in the fluorescence emission concurrent with stimulus onset and offset were recorded from the labeled neurons in the current study. The fairly slow time course of the fluorescence signal did not allow for the recording of individual action potentials. This is also the case for the more recently developed fluorescent calcium sensors based on the calcium binding protein troponin C (Mank et al., 2008), which demonstrate relatively slow kinetics. Furthermore, the peak change in fluorescence of voltage sensitive dyes and proteins is at least an order of magnitude smaller than the signal observed with typical calcium indicator dyes (Hendel et al., 2008). Whether enough photons can be generated in a time window short enough to resolve individual action potentials by newer voltage or calcium sensors will depend critically on the density of sensor molecules, the efficiency of fluorescence excitation, the degree of modulation of fluorescence by voltage or calcium, and the efficiency of the detectors. Recent developments of the GCamp calcium indicator family show promising temporal resolution and signal to noise ratio (Tian et al., 2009; Looger and Griesbeck, 2011), which might allow detection of individual action potentials from the fluorescence signal. Novel proteins, for example C. intestinalis voltage-sensor-containing phosphatase (Ci-VSP), which translates transmembrane voltage changes into the turnover of phosphoinositides (Murata et al., 2005; Lundby et al., 2010), and microbial rhodopsins (Kralj et al., 2011) offer viable alternatives to the Shaker family with improvements in sensitivity and speed (Mutoh et al., 2011).

In fixed tissue using confocal microscopy, Flare expressing neurons displayed fluorescence labeling in the cell membrane. However, high magnification two-photon images of Flare neurons in vivo mostly revealed cell bodies and occasional processes, whereas the membrane labeling was difficult to detect. It is possible to envision other constructs of Flare that would direct it to particular membrane or peri-membrane locations (Guerrero 
et al., 2005). Increased density of Flare in the membrane should lead to higher signals, and also might improve signal strength. It is noteworthy in this respect that increased synthesis of Flare alone might not be productive as there could be a high concentration of Flare associated with intracellular membrane, such as the ER. Signal strength might be further affected by functionality of the Kv1.4 channels (Zhu et al., 2003; Jenkins et al., 2011). For example, it is hypothetized that the FlaSh or Flare subunits can co-assemble with compatible native subunits of the Kv1 subfamily (Guerrero et al., 2002). Due to the high levels of expression of Flare expected with Sindbis, it is anticipated that many of the Kv1.4 channels will be either heteromeres with a majority of Flare sub-units, or homomeres. It has been suggested that assemblies of different subunits can produce channels with distinct kinetics and pharmacology (Isacoff et al., 1990).

\section{VECTORS FOR TRANSFECTION: NEURONAL SPECIFICITY}

In the current study, Sindbis was used as viral vector for transforming neurons. In cell culture, Sindbis is known to damage cells or cause apoptosis as early as $12 \mathrm{~h}$ after infection through NMDA (Nargi-Aizenman and Griffin, 2001). In our hands, Sindbis Flare permits labeling of neurons that may be recorded up to $36 \mathrm{~h}$ following transfection. There were few signs of damage to the neurons in this time window including morphological abnormalities or blebbing. Successful transfection of neurons using Sindbis without evidence of cell damage or necrosis more than one day after transfection has been demonstrated previously (Chen et al., 2000; Diaz et al., 2004). It may be that the extracellular milieu provides protection to the neurons via circulating anti-oxidant protective factors. This fast expression time period is useful when examining short-term plasticity questions and immediate sensory evoked response properties, but its greatest value may be for the rapid assessment of novel biosensor proteins. Recent developments have generated Sindbis virus with decreased neurotoxicity, which allow longer expression times and viable neurons for up to one week after infection (Jeromin et al., 2003; Kim et al., 2004)

The histology indicates that Sindbis Flare primarily labeled pyramidal neurons in rat cortex, as demonstrated previously using Sindbis EGFP (Chen et al., 2000). We base this conclusion primarily on the morphology of neurons as evidenced in fixed tissue using fluorescence or confocal microscopy. There was no evidence that glial cells were labeled based on the cell morphology. Earlier studies comparing different viral vectors confirm that more than $90 \%$ of infected cells showed neuronal morphology (Ehrengruber et al., 1999). Selective expression (i.e., transfection of specific cell types) will allow targeting of neuronal subpopulation and ensure that only neurons are labeled. Recent studies demonstrate that depending on virus type and titer specific neuronal subpopulations can be transfected (Nathanson et al., 2009b). In addition, adeno-associated viruses $(\mathrm{AAV})$ of various serotypes are known to infect different cell types based upon cell surface antigens (Cearley and Wolfe, 2006; Wu et al., 2006; Taymans et al., 2007). Furthermore, cell type specificity may be approached on the basis of neuronal anatomy; retrograde labeling by infecting cells via their axon terminals, can access specific anatomical projection classes
(Burger et al., 2004). In addition, cell type specificity has been attempted by inclusion of specific promoters and enhancers (Morelli et al., 1999; Nathanson et al., 2009a). Finally, transgenic mice in which GABA-ergic neurons express GFP further allow labeling and imaging of specific neuron types (Sohya et al., 2007).

\section{SUITABILITY OF SINDBIS FLARE AS A GENETICALLY ENCODED FLUORESCENCE VOLTAGE SENSOR}

In the current study, about $15 \%$ of labeled cells responded to the onset of the full field visual stimulus composed of several wavelengths. This relatively low number has been commonly observed in genetically encoded fluorescent sensors in cortex, for example, for the virally transfected neurons in mouse visual cortex expressing the calcium sensor TNXXL (Mank et al., 2008).

Several factors can account for this relatively low percentage of responsive neurons. First, the flashed stimulus may have not been optimal. A study of single unit activity using a variety of stimuli in rat visual cortex found that $11 \%$ of units responded optimally to uniform stimulation. The majority of cells preferred structured stimuli with low spatial frequencies (Girman et al., 1999). A recent fMRI study in rats found reliable hemodynamic and electrical (multiunit) activation using full-field stimulation with LEDs of varying wavelength (Bailey et al., 2012). In our study, intrinsic optical imaging in rat visual cortex showed reliable functional activation using full field stimuli, which was confirmed by visually evoked potentials (You et al., 2011). Thus, the visual stimulation in the current study was suitable to elicit neural responses but could be further improved by incorporating structured stimuli such as gratings. Second, neural responsiveness also depends on the state of cortex (Hasenstaub et al., 2007), which can be strongly affected by anesthesia, with deep anesthesia significantly blocking signal propagation through a cortical network (Ahrens and Freeman, 2001). Nonetheless, other rodent studies using various forms of anesthesia yielded relatively high percentages of visually responsive neurons (Ohki et al., 2005; Niell and Stryker, 2008). Fluctuations in anesthesia could also be responsible for the observed variability of the intrinsic signal time course (Martin et al., 2006; Devonshire et al., 2010). Third, the relatively small number and substantial averaging needed to extract stimulusevoked signals may arise from the limited quantity of fluorescent protein that is being imaged; the functional Flare signal is largely obtained from the cell membrane, thus reducing the labeled area that can be scanned.

While the current generation of genetically encoded voltage sensors all have a smaller signal to noise ratio compared to calcium sensors, further development of membrane targeted sensors will likely result in stronger signals to provide reliable measures of neuronal activity. The advantage of voltage-based sensors over calcium sensors is the potential for much faster measurements that could, in principle, permit the detection of single action potentials. In the current and other studies (Akemann et al., 2010) using living animals, the measured increase in fluorescence from visual stimulation showed slower kinetics compared to in vitro studies. The specific kinetics of Flare are not known but different versions of FlaSh have demonstrated large variability in kinetics and signal amplitude (Guerrero et al., 2002; Jin et al., 2011). 
Current voltage sensitive dyes provide a strong signal and allow imaging of large neuronal populations (Slovin et al., 2002; Grinvald et al., 2003). Bulk loading is required for applying these dyes and thus does not permit selective targeting of specific neuron types. Similarly, cell permeant calcium indicators are characterized by strong signal and labeling of large numbers of neurons of which up to $75 \%$ are responsive (Ohki et al., 2005). Again, the downside is the lack of specificity of the calcium indicator labeling (Sohya et al., 2007; Takahashi et al., 2007). Thus, one of the main advantages of the genetic encoding approach is the specificity of single neuron molecular genetics. In addition, if using appropriate viral vectors (e.g., AAV), genetically encoded sensors also allow long-term monitoring as they can permanently label neurons without causing cell damage (Heider et al., 2010). Thus, evaluating Sindbis Flare in a rodent model represents a crucial step in improving fidelity of these sensors and allows applications in various species. The current study clearly demonstrates that Sindbis Flare showed superior performance compared to previous reports using preparations such as in vitro studies in dissociated hippocampal neurons. Thus, sensors of newer generations need to

\section{REFERENCES}

Ahrens, K. F., and Freeman, W. J. (2001). Response dynamics of entorhinal cortex in awake, anesthetized, and bulbotomized rats. Brain Res. 911, 193-202.

Akemann, W., Mutoh, H., Perron, A., Rossier, J., and Knöpfel, T. (2010). Imaging brain electric signals with genetically targeted voltagesensitive fluorescent proteins. Nat. Methods 7, 643-649.

Ataka, K., and Pieribone, V. A. (2002). A genetically targetable fluorescent probe of channel gating with rapid kinetics. Biophys. J. 82, 509-516.

Bailey, C. J., Sanganahalli, B. G., Herman, P., Blumenfeld, H., Gjedde, A., and Hyder, F. (2012). Analysis of time and space invariance of BOLD responses in the rat visual system. Cereb. Cortex. doi: 10.1093/cercor/bhs008 [Epub ahead of print]

Baker, B., Mutoh, H., Dimitrov, D., Akemann, W., Perron, A., Iwamoto, Y., Jin, L., Cohen, L., Isacoff, E., Pieribone, V., Hughes, T., and Knöpfel, T. (2008). Genetically encoded fluorescent sensors of membrane potential. Brain Cell Biol. 36, 53-67.

Baker, B. J., Lee, H., Pieribone, V. A., Cohen, L. B., Isacoff, E. Y., Knöpfel, T., and Kosmidis, E. K. (2007). Three fluorescent protein voltage sensors exhibit low plasma membrane expression in mammalian cells. J. Neurosci. Methods 161, 32-38.

Blood, A. J., Narayan, S. M., and Toga, A. W. (1995). Stimulus parameters influence characteristics of optical intrinsic signal responses in somatosensory cortex. J. Cereb. Blood Flow Metab. 15, 1109-1121.

Burger, C., Gorbatyuk, O. S., Velardo, M. J., Peden, C. S., Williams, P., Zolotukhin, S., Reier, P. J., Mandel, R. J., and Muzyczka, N. (2004). Recombinant AAV viral vectors pseudotyped with viral capsids from serotypes 1,2 , and 5 display differential efficiency and cell tropism after delivery to different regions of the central nervous system. Mol. Ther. 10, 302-317.

Cearley, C. N., and Wolfe, J. H. (2006). Transduction characteristics of adeno-associated virus vectors expressing cap serotypes $7,8,9$, and Rh10 in the mouse brain. Mol. Ther. 13, 528-537.

Ch'ng, Y. H., and Reid, C. (2011). Cellular imaging of visual cortex reveals the spatial and functional organization of spontaneous activity. Front. Integr. Neurosci. 4:20. doi: $10.3389 /$ fnint. 2010.00020

Chamberlin, N. L., Du, B., De Lacalle, S., and Saper, C. B. (1998). Recombinant adeno-associated virus vector: use for transgene expression and anterograde tract tracing in the CNS. Brain Res. 793, 169-175.

Chen, B. E., Lendvai, B., Nimchinsky, E. A., Burbach, B., Fox, K., and Svoboda, K. (2000). Imaging high-resolution structure of GFPexpressing neurons in neocortex in vivo. Learn. Mem. 7, 433-441.

Crick, F. (1979). Thinking about the brain. Sci. Am. 241, 219-232.

Denk, W., Delaney, K. R., Gelperin, A., Kleinfeld, D., Strowbridge, B. W.,

be evaluated using a variety of preparations and species (Perron et al., 2009a; Jin et al., 2011).

Genetically encoded sensors of both voltage and calcium will allow further advances as the means to select the transformed neuronal population develop. Neuronal populations can be selected using anterograde (Chamberlin et al., 1998) and retrograde (Lu et al., 2003) transfection. Similarly, a modified rabies vector permits labeling based on connectivity (Wickersham et al., 2007). These molecular approaches applied to systems neuroscience, as predicted by Francis Crick 30 years ago (Crick, 1979), will transform our view of the role of the circuit in generating perception and action.

\section{ACKNOWLEDGMENTS}

Initial assistance in our two-photon imaging efforts by Samar Mehta, Phil Tsai, and David Kleinfeld are gratefully appreciated. This work was supported by the National Institutes of Health Grants EY-R03EY014657 (RMS), R01NS050833 (EYI, RMS), The Whitehall Foundation (RMS), National Science Foundation Grant NPACI RUT223 (RMS).

Tank, D. W., and Yuste, R. (1994). Anatomical and functional imaging of neurons using 2-photon laser scanning microscopy. J. Neurosci. Methods 54, 151-162.

Devonshire, I. M., Grandy, T. H., Dommett, E. J., and Greenfield, S. A. (2010). Effects of urethane anaesthesia on sensory processing in the rat barrel cortex revealed by combined optical imaging and electrophysiology. Eur. J. Neurosci. 32, 786-797.

Diaz, L. M., Maiya, R., Sullivan, M. A., Han, Y., Walton, H. A., Boehm, S. L., Bergeson, S. E., Mayfield, R. D., and Morrisett, R. A. (2004). Sindbis viral-mediated expression of eGFPdopamine D1 receptors in situ with real-time two-photon microscopic detection. J. Neurosci. Methods 139, 25-31.

Ehrengruber, M. U., Lundstrom, K., Schweitzer, C., Heuss, C., Schlesinger, S., and Gähwiler, B. H. (1999). Recombinant Semliki Forest virus and Sindbis virus efficiently infect neurons in hippocampal slice cultures. Proc. Natl. Acad. Sci. U.S.A. 96, 7041-7046.

Girman, S. V., Sauve, Y., and Lund, R. D. (1999). Receptive field properties of single neurons in rat primary visual cortex. J. Neurophysiol. 82, 301-311.

Grinvald, A., Arieli, A., Tsodyks, M., and Kenet, T. (2003). Neuronal assemblies: single cortical neurons are obedient members of a huge orchestra. Biopolymers 68, 422-436.

Guerrero, G., Rieff, D. F., Agarwal, G., Ball, R. W., Borst, A., Goodman, C. S., and Isacoff, E. Y. (2005)
Heterogeneity in synaptic transmission along a Drosophila larval motor axon. Nat. Neurosci. 8, 1188-1196.

Guerrero, G., Siegel, M. S., Roska, B., Loots, E., and Isacoff, E. Y. (2002). Tuning FlaSh: redesign of the dynamics, voltage range, and color of the genetically encoded optical sensor of membrane potential. Biophys. J. 83, 3607-3618.

Hasenstaub, A., Sachdev, R. N. S., and McCormick, D. A. (2007). State changes rapidly modulate cortical neuronal responsiveness. J. Neurosci. 27, 9607-9622.

Heider, B., Jando, G., and Siegel, R. M. (2005). Functional architecture of retinotopy in visual association cortex of behaving monkey. Cereb. Cortex 15, 460-478.

Heider, B., Nathanson, J. L., Isacoff, E. Y., Callaway, E. M., and Siegel, R. M. (2010). Two-photon imaging of calcium in virally transfected striate cortical neurons of behaving monkey. PLoS One 5:e13829. doi: 10.1371/journal.pone.0013829

Hendel, T., Mank, M., Schnell, B., Griesbeck, O., Borst, A., and Reiff, D. F. (2008). Fluorescence changes of genetic calcium indicators and OGB-1 correlated with neural activity and calcium in vivo and in vitro. J. Neurosci. 28, 7399-7411.

Isacoff, E. Y., Jan, Y. N., and Jan, L. Y. (1990). Evidence for the formation of heteromultimeric potassium channels in Xenopus oocytes. Nature 345, 530-534.

Jacobs, G. H., Fenwick, J. A., and Williams, G. A. (2001). Cone-based vision of rats for ultraviolet and 
visible lights. J. Exp. Biol. 204, 2439-2446.

Jenkins, P. M., McIntyre, J. C., Zhang, L., Anantharam, A., Vesely, E. D., Arendt, K. L., Carruthers, C. J. L., Kerppola, T. K., Iñiguez-Lluhí, J. A., Holz, R. W., Sutton, M. A., and Martens, J. R. (2011). Subunitdependent axonal trafficking of distinct $\alpha$ heteromeric potassium channel complexes. J. Neurosci. 31, 13224-13235.

Jeromin, A., Yuan, L.-L., Frick, A., Pfaffinger, P., and Johnston, D. (2003). A modified sindbis vector for prolonged gene expression in neurons. J. Neurophysiol. 90, 2741-2745.

Jin, L., Baker, B., Mealer, R., Cohen, L., Pieribone, V., Pralle, A., and Hughes, T. (2011). Random insertion of split-cans of the fluorescent protein venus into Shaker channels yields voltage sensitive probes with improved membrane localization in mammalian cells. J. Neurosci. Methods 199, 1-9.

Jung, J. C., Mehta, A. D., Aksay, E., Stepnoski, R., and Schnitzer, M. J. (2004). In vivo mammalian brain imaging using one- and two-photon fluorescence microendoscopy. J. Neurophysiol. 92, 3121-3133.

Kim, J., Dittgen, T., Nimmerjahn, A., Waters, J., Pawlak, V., Helmchen, F., Schlesinger, S., Seeburg, P. H., and Osten, P. (2004). Sindbis vector SINrep(nsP2S726): a tool for rapid heterologous expression with attenuated cytotoxicity in neurons. J. Neurosci. Methods 133, 81-90.

Kralj, J. M., Douglass, A. D., Hochbaum, D. R., Maclaurin, D., and Cohen, A. E. (2011). Optical recording of action potentials in mammalian neurons using a microbial rhodopsin. Nat. Methods 9, 90-95.

Levene, M. J., Dombeck, D. A., Kasischke, K. A., Molloy, R. P., and Webb, W. W. (2004). In vivo multiphoton microscopy of deep brain tissue. J. Neurophysiol. 91, 1908-1912.

Liu, X., Gong, H., Li, X., and Zhou, W. (2008). Monitoring calcium concentration in neurons with Cameleon. J. Biosci. Bioeng. 105, 106-109.

Looger, L. L., and Griesbeck, O. (2011). Genetically encoded neural activity indicators. Curr. Opin. Neurobiol. 22, 18-23.

Lu, Y.-Y., Wang, L.-J., Muramatsu, S.-I., Ikeguchi, K., Fujimoto, K.-I., Okada, T., Mizukami, H., Matsushita, T., Hanazono, Y., Kume, A., Nagatsu, T., Ozawa, K., and Nakano, I. (2003). Intramuscular injection of AAV-GDNF results in sustained expression of transgenic GDNF, and its delivery to spinal motoneurons by retrograde transport. Neurosci. Res. 45, 33-40.

Lundby, A., Akemann, W., and Knöpfel, T. (2010). Biophysical characterization of the fluorescent protein voltage probe VSFP2.3 based on the voltage-sensing domain of Ci-VSP. Eur. Biophys. J. 39, 1625-1635.

Mank, M., Santos, A. F., Direnberger, S., Mrsic-Flogel, T. D., Hofer, S. B., Stein, V., Hendel, T., Reiff, D. F., Levelt, C., Borst, A., Bonhoeffer, T., Hubener, M., and Griesbeck, O. (2008). A genetically encoded calcium indicator for chronic in vivo two-photon imaging. Nat. Methods 5, 805-811.

Marshel, J. H., Mori, T., Nielsen, K. J., and Callaway, E. M. (2010). Targeting single neuronal networks for gene expression and cell labeling in vivo. Neuron 67, 562-574.

Martin, C., Martindale, J., Berwick, J., and Mayhew, J. (2006). Investigating neural-hemodynamic coupling and the hemodynamic response function in the awake rat. Neuroimage 32, 33-48.

Morelli, A. E., Larregina, A. T., SmithArica, J., Dewey, R. A., Southgate, T. D., Ambar, B., Fontana, A., Castro, M. G., and Lowenstein, P. R. (1999). Neuronal and glial cell type-specific promoters within adenovirus recombinants restrict the expression of the apoptosisinducing molecule Fas ligand to predetermined brain cell types, and abolish peripheral liver toxicity. J. Gen. Virol. 80, 571-583.

Mrsic-Flogel, T. D., Hofer, S. B., Ohki, K., Reid, R. C., Bonhoeffer, T., and Hubener, M. (2007). Homeostatic regulation of eye-specific responses in visual cortex during ocular dominance plasticity. Neuron 54, 961-972.

Murata, Y., Iwasaki, H., Sasaki, M., Inaba, K., and Okamura, Y. (2005). Phosphoinositide phosphatase activity coupled to an intrinsic voltage sensor. Nature 435, 1239-1243.

Mutoh, H., Perron, A., Akemann, W., Iwamoto, Y., and Knöpfel, T. (2011). Optogenetic monitoring of membrane potentials. Exp. Physiol. 96, 13-18.

Nargi-Aizenman, J. L., and Griffin, D. E. (2001). Sindbis virus-induced neuronal death is both necrotic and apoptotic and is ameliorated bynmethyl-d-aspartate receptor antagonists. J. Virol. 75, 7114-7121.
Nathanson, J. L., Jappelli, R., Scheeff, E. D., Manning, G., Obata, K. Brenner, S., and Callaway, E. M. (2009a). Short promoters in viral vectors drive selective expression in mammalian inhibitory neurons, but do not restrict activity to specific inhibitory cell-types. Front. Neural Circuits 5:12. doi: 10.3389/neuro.04.019.2009

Nathanson, J. L., Yanagawa, Y., Obata, K., and Callaway, E. M. (2009b). Preferential labeling of inhibitory and excitatory cortical neurons by endogenous tropism of adenoassociated virus and lentivirus vectors. Neuroscience 161, 441-450.

Nguyen, Q.-T., Tsai, P. S., and Kleinfeld, D. (2006). MPScope: a versatile software suite for multiphoton microscopy. J. Neurosci. Methods 156, 351-359.

Niell, C. M., and Stryker, M. P. (2008). Highly selective receptive fields in mouse visual cortex. J. Neurosci. 28 7520-7536.

Ohki, K., Chung, S., Ch'ng, Y. H., Kara, P., and Reid, R. C. (2005). Functional imaging with cellular resolution reveals precise microarchitecture in visual cortex. Nature 433, 597-603

Perron, A., Mutoh, H., Akemann, W., Gautam, S. G., Dimitrov, D., Iwamoto, Y., and Knöpfel, T. (2009a). Second and third generation voltage-sensitive fluorescent proteins for monitoring membrane potential. Front. Mol. Neurosci. 2:5 doi: 10.3389/neuro.02.005.2009

Perron, A., Mutoh, H., Launey, T., and Knöpfel, T. (2009b). Red-shifted voltage-sensitive fluorescent proteins. Chem. Biol. 16, 1268-1277.

Reiff, D. F., Ihring, A., Guerrero, G. Isacoff, E. Y., Joesch, M., Nakai, J., and Borst, A. (2005). In vivo performance of genetically encoded indicators of neural activity in flies. J. Neurosci. 25, 4766-4778.

Sheng, M., Tsaur, M. L., Jan, Y. N., and Jan, L. Y. (1994). Contrasting subcellular localization of the Kv1.2 K+ channel subunit in different neurons of rat brain. J. Neurosci. 14, 2408-2417.

Siegel, M. S., and Isacoff, E. Y. (1997). A genetically encoded optical probe of membrane voltage. Neuron 19, 735-741.

Siegel, R. M., Ahrens, K. F., Lee, H., Dean, C. B., and Isacoff, E. Y. (2007). "In vivo intrinsic and stimulus induced modulation of rat visual cortex neurons assessed with a genetically encoded fluorescent voltage sensor and twophoton imaging," in Program No.
451.12007 Neuroscience Meeting Planner, (San Diego, CA: Society for Neuroscience). [Online].

Siegel, R. M., Raffi, M., Phinney, R. E., Turner, J. A., and Jando, G. (2003). Functional architecture of eye position gain fields in visual association cortex of behaving monkey. J. Neurophysiol. 90, 1279-1294

Simons, S. B., Chiu, J., Favorov, O. V., Whitsel, B. L., and Tommerdahl, M. (2007). Duration-dependent response of si to vibrotactile stimulation in squirrel monkey. J. Neurophysiol. 97, 2121-2129.

Slovin, H., Arieli, A., Hildesheim, R., and Grinvald, A. (2002). Longterm voltage-sensitive dye imaging reveals cortical dynamics in behaving monkeys. J. Neurophysiol. 88, 3421-3438.

Sohya, K., Kameyama, K., Yanagawa, Y., Obata, K., and Tsumoto, T. (2007). GABAergic neurons are less selective to stimulus orientation than excitatory neurons in layer II/III of visual cortex, as revealed by in vivo functional $\mathrm{Ca} 2+$ imaging in transgenic mice. J. Neurosci. 27, 2145-2149.

Stosiek, C., Garaschuk, O., Holthoff, K., and Konnerth, A. (2003). In vivo two-photon calcium imaging of neuronal networks. Proc. Natl. Acad. Sci. U.S.A. 100, 7319-7324.

Takahashi, N., Sasaki, T., Usami, A., Matsuki, N., and Ikegaya, Y. (2007). Watching neuronal circuit dynamics through functional multineuron calcium imaging (fMCI). Neurosci. Res. 58, 219-225.

Taymans, J.-M., Vandenberghe, L. H., Haute, C. V. D., Thiry, I., Deroose, C. M., Mortelmans, L., Wilson, J. M., Debyser, Z., and Baekelandt, V. (2007). Comparative analysis of adeno-associated viral vector serotypes $1,2,5,7$, and 8 in mouse brain. Hum. Gene Ther. 18, 195-206.

Tian, L., Hires, S. A., Mao, T., Huber, D., Chiappe, M. E., Chalasani, S. H., Petreanu, L., Akerboom, J., Mckinney, S. A., Schreiter, E. R., Bargmann, C. I., Jayaraman, V., Svoboda, K., and Looger, L. L. (2009). Imaging neural activity in worms, flies and mice with improved GCaMP calcium indicators. Nat. Methods 6, 875-881.

Tsai, P. S., Nishimura, N., Yoder, E. J., While, A., Dolnick, E., and Kleinfeld, D. (2002). "Principles, design and construction of a twophoton scanning microscope for in vivo and in vitro studies," in Methods for In Vivo Optical Imaging, ed. R. Frostig (Boca Raton, FL: CRC Press), 113-171. 
Walikonis, R. S., Jensen, O. N., Mann, M., Provance, D. W., Mercer, J. A., and Kennedy, M. B. (2000). Identification of proteins in the postsynaptic density fraction by mass spectrometry. J. Neurosci. 20, 4069-4080.

Wang, G., Nagai, M., and Okamura, J. (2011). Orientation dependency of intrinsic optical signal dynamics in cat area 18. Neuroimage 57, 1140-1153.

Wickersham, I. R., Lyon, D. C., Barnard, R. J. O., Mori, T., Finke, S., Conzelmann, K.-K., Young, J. A. T., and Callaway, E. M. (2007). Monosynaptic restriction of transsynaptic tracing from single, genetically targeted neurons. Neuron 53, 639-647.
Wu, Z., Asokan, A., and Samulski, R. J. (2006). Adeno-associated virus serotypes: vector toolkit for human gene therapy. Mol. Ther. 14, 316-327.

Xiao, X., Li, J., and Samulski, R. J. (1998). Production of high-titer recombinant adeno-associated virus vectors in the absence of helper adenovirus. J. Virol. 72, 2224-2232.

$\mathrm{Xu}, \mathrm{X}$., and Callaway, E. M. (2009). Laminar specificity of functional input to distinct types of inhibitory cortical neurons. J. Neurosci. 29, 70-85.

Xu, X., Roby, K. D., and Callaway, E. M. (2006). Mouse cortical inhibitory neuron type that coexpresses somatostatin and calretinin. J. Comp. Neurol. 499, 144-160.
You, Y., Klistorner, A., Thie, J., and Graham, S. (2011). Improving reproducibility of VEP recording in rats: electrodes, stimulus source and peak analysis. Doc. Ophthalmol. 123, 109-119.

Zhu, J., Watanabe, I., Gomez, B. and Thornhill, W. B. (2003). Heteromeric Kv1 potassium channel expression: amino acid determinants involved in processing and trafficking to the cell surface. J. Biol. Chem. 278, 25558-25567.

Conflict of Interest Statement: The authors declare that the research was conducted in the absence of any commercial or financial relationships that could be construed as a potentia conflict of interest.
Received: 04 January 2012; accepted: 05 March 2012; published online: 22 March 2012.

Citation: Ahrens KF, Heider B, Lee $H$, Isacoff EY and Siegel RM (2012) Two-photon scanning microscopy of in vivo sensory responses of cortical neurons genetically encoded with a fluorescent voltage sensor in rat. Front. Neural Circuits 6:15. doi: 10.3389/fncir. 2012.00015

Copyright (c) 2012 Ahrens, Heider, Lee, Isacoff and Siegel. This is an openaccess article distributed under the terms of the Creative Commons Attribution Non Commercial License, which permits non-commercial use, distribution, and reproduction in other forums, provided the original authors and source are credited. 